Most rating values will, therefore, be close to the mean but there is a high probability of one or more outlying points occurring. This will cause statistically significant, but spurious, correlations.

Taking all of this into consideration, I agree with the authors' conclusion that "Further research is clearly needed to substantiate these results".

Bill Plummer

Community Mental Health Centre

8, Radnor Park Avenue

Folkestone

Kent

\section{Prevalence and incidence of schizophrenia in Afro-Caribbeans}

SIR: The recent articles by Wessely et al (Journal, December 1991, 159, 795-801) and Castle et al (Journal, December 1991, 159, 790-794) describing increased incidence of schizophrenia in those of Afro-Caribbean origin, and Eagles' description of the possible alternatives to psychosocial explanations (Journal, December 1991, 159, 783-789) raise a number of issues.

A recent epidemiological study on the Caribbean island of Dominica showed that over a 30-month period the age-corrected prevalence rate for schizophrenia by ICD-9 diagnosis was $11.8 / 1000$ (Kay, 1990). This figure was obtained from a computerised case register of all admissions, out-patient referrals and prison consultations supplemented by the use of key informants in every major village. When DSMIII diagnostic criteria were applied, the prevalence decreased to 7.8/1000. Given the limitations of case finding in this study, the rates found by either diagnostic system are significantly higher than those generally found in the UK.

Incidence rates for schizophrenia in Dominica in 1989, using the same case register were, by ICD-9 $14.8 / 10000$, and using DSM-III criteria $7.3 / 10000$, which are considerably higher than comparative figures in Camberwell for the total population (Castle et al) by a factor of 6 to 8 , but closer to the increased risk ratio of schizophrenia if of AfroCaribbean origin (Wessely et $a$ ). The smaller proportion of ICD-9 cases meeting DSM-III criteria in Camberwell may reflect possible diagnostic bias and, in particular, cases of affective psychosis may masquerade as paranoid schizophreniform psychoses possibly as a result of culturally determined projective defence mechanisms being more prevalent in Afro-Caribbeans.

If results from one island state can be generalised to the Caribbean region this would suggest that the increased risk of schizophrenia meeting DSM-III criteria in the UK for those of Afro-Caribbean origin must be explained by factors operating both in the UK and the country of origin, and not the potentially racially prejudiced interaction with the UK mental health care system. Possible explanations include those factors discussed by Eagles. With increasing immunisation rates, and obstetric care approaching UK levels in Dominica (McIntyre, 1988), it will be interesting to observe if there is any decrease in the incidence of schizophrenia in the next 15 to 20 years. Increased genetic risk is possible but unlikely given low reported rates of schizophrenia in West Africa (Sikanertey \& Eaton, 1984) where most AfroCaribbeans originate, and theories based on concentration of genetic factors in small gene pools are unlikely given low rates of other congenital diseases.

A major culturally determined factor in my experience is that the consumption of large amounts of cannabis can act as both a precipitant of schizophreniform psychoses and as a factor in causing relapse and maintaining chronicity, in pre-existing schizophrenia, although the published literature is contradictory. This may partially explain the high incidence and prevalence rates found in Dominica if not to the same extent those found in Camberwell, where cannabis consumption may be assumed to be lower. However, this is an area requiring further study.

KAY, R. W. (1990) Prevalence of psychotic mental disorders in the Commonwealth of Dominica (Abstract) West Indian Medical Journal, 39 (suppl.1), 30-31.

MCINTYRE, D. O. N. (1988) In Annual Report of the Chief Medical Officer for the year 1987. Dominica: Ministry of Health.

SikANERTEY, T. \& Eaton, W. W. (1984) Prevalence of schizophrenia in the Labadi District of Ghana. Acta Psychiatrica Scandinavica 69, 156-161.

The Royal Edinburgh Hospital

RONALD W. KaY

Morningside Place

Edinburgh

EHIO 5HF

\section{Monsieur Pascal's cognitive therapy?}

SIR: I was intrigued recently to read the following and to note the similarities that there are with the concepts that underlie 'modern' cognitive therapies.

\footnotetext{
"The nature of man is so framed, that not only by often hearing himself a fool, he believes it; but by often calling himself a fool, he enters into the same opinion. Every person holds an inward and secret conversation with his own breast, and such as it highly concerns him well to regulate, because even in this sense, evil communications corrupt good manners. To study silence as much as possible and to converse with God alone, is the true persuasion in respect of ourselves."
} 